\title{
Quantitative Assessment of Vulnerability to Flood Hazards in Downstream Area of Mono Basin, South-Eastern Togo: Yoto District
}

\author{
Abravi Essenam Kissi 1* ${ }^{*}$, Georges Abbevi Abbey², Komi Agboka², Aklesso Egbendewe ${ }^{3}$ \\ ${ }^{1}$ Département de Géographie, WASCAL, Université de Lomé, Lomé, Togo \\ ${ }^{2}$ Ecole Supérieure d'Agronomie, Université de Lomé, Lomé, Togo \\ ${ }^{3}$ Faculté des Sciences Economiques et de Gestion, Université de Lomé, Lomé, Togo \\ Email: "elvire.kissi@yahoo.com, george_abbey2@yahoo.fr, kagboka@gmail.com, emaklesso@gmail.com
}

Received 5 October 2015; accepted 20 December 2015; published 23 December 2015

Copyright (C) 2015 by authors and Scientific Research Publishing Inc.

This work is licensed under the Creative Commons Attribution International License (CC BY). http://creativecommons.org/licenses/by/4.0/

(c) (i) Open Access

\section{Abstract}

The population located along Mono River in the Yoto district faces great challenges in terms of repeated flood disasters in recent years. This paper aims at assessing the conditions which influence flood damage in the study area by using indicators to compute a Flood Vulnerability Index (FVI). The study relies on Turner et al.'s vulnerability framework and distinguishes three main components (exposure, susceptibility and resilience) that allow a more in-depth analysis and interpretation of local indicators. As a result flood disaster in the study area is not only due to the extreme variability in terms of flood magnitude and frequency in the Mono River, but also to the interaction between human and the environment. The lack of vegetation along the river bank, the closeness of households' farmlands to the river body, the type of construction and the position of settlements, the household size, the low level education of household head, the lack of diversification of livelihood strategies, the lack of adequate flood warning system, the lack of willingness and ability to take responsive actions coupled with inadequate emergency services, are identified as main determinants increasing communities' vulnerability to flood disaster. Furthermore, the computation of Flood Vulnerability Index (FVI) offers easy comparison of communities' vulnerability to flood disaster and pinpoints the most vulnerable communities. At the end of the study, flood exposure, susceptibility, resilience and vulnerability maps were generated.

\section{Keywords}

Assessment, Flood, Quantitative Vulnerability, Downstream, Mono River Basin, Yoto District

\footnotetext{
${ }^{*}$ Corresponding author.
}

How to cite this paper: Kissi, A.E., Abbey, G.A., Agboka, K. and Egbendewe, A. (2015) Quantitative Assessment of Vulnerability to Flood Hazards in Downstream Area of Mono Basin, South-Eastern Togo: Yoto District. Journal of Geographic Information System, 7, 607-619. http://dx.doi.org/10.4236/igis.2015.76049 


\section{Introduction}

Floods are among the most recurring and devastating natural hazards, impacting human lives and causing severe economic damage throughout the world [1]. Flood disasters are occurring as a consequence of either natural factors, such as climate change and climate variability or anthropogenic factors, such as socio-economic and land-use developments [2]. They are characterised by long, short and no warning, depending on the type of floods, speed or onset which may be gradual or sudden [3]. They may result in loss of life, damage to property and destruction of the environment and make the number of people at risk in developing countries more vulnerable to flood disasters due to their high poverty level.

Climate change scenarios predict increase in both the frequency and the severity of flood hazards in West Africa [4], likewise in Togo. During the recent years, floods occur repeatedly in Togo and cause tremendous losses in terms of property and life, particularly in the lowland areas of the country. Flooding due to excessive rainfall in a short period of time is a frequent hazard in the flood plains of Mono River in Yoto District during monsoon. It inflicts significant environmental, social, and economic damages and affects population safety. The focus of this study is to conduct flood vulnerability assessment of the downstream area in Mono River basin in the Yoto district through indicator-based vulnerability criteria as proactive response to floods.

\section{Material and Methods}

\subsection{Study Area}

The study was conducted in Yoto district located in North-East of the Maritime region. The district is geographically bound by latitude $6^{\circ} 30^{\prime} \mathrm{N}$ and $6^{\circ} 60^{\prime} \mathrm{N}$, longitude $1^{\circ} 20^{\prime} \mathrm{E}$ and $1^{\circ} 35^{\prime} \mathrm{E}$. The Mono River system is the largest river system in Togo with catchments area of $21,500 \mathrm{~km}^{2}$; it serves as eastern boundary between the Yoto district and the Republic of Benin. Eight villages from three counties have been selected Sedome (Mawussou, Djrekpon, Batoe), Esse-Godjin (Tofakope, Atikpatafo), and Tokpli (Kpodji, Tchakponou-kondji and Logokpo) for the present study (Figure 1). They are located in the catchment area of the Mono River, where populations have been affected, especially during 2010 flood event, providing then a better study population which can help us to generate a better view on the assessment conducted.

The study area, which is at an altitude that ranges from 17 to 55 meters above sea level, has Guinean subequatorial climate. The mean annual temperature ranges from $22^{\circ} \mathrm{C}$ to $30^{\circ} \mathrm{C}$ and precipitation varies between 800 $\mathrm{mm}$ and $1200 \mathrm{~mm} /$ year; this usually peaks in May-June and September-October.

The Mono River has passed from the irregular to a relatively regular flow due to the release of water of Nangbéto dam constructed in 1987 for hydroelectric purposes. Prior to the construction of the Nangbéto dam, the Mono River presented phases of low water flow with null flow from mid-December to the third week of May, and high water flow from May until December the river with average maximum of (450 $\left.\mathrm{m}^{3} / \mathrm{s}\right)$ in September.

This is changed after the construction of the dam with a relatively permanent out-flows at the downstream area [5].

According to the 2010 National census, total population of the study area was estimated at about 34,918 with 10,803 in Sedome, 9261 in Esse-Godjin and 14,854 in Tokpli representing the three counties surveyed. The majority of this population is located in the River floodplains. Agriculture is the main activity being carried out in the area with most people practising subsistence farming. The main crops grown in the area include maize, cassava, sugarcane, beans, groundnut, palm trees and various traditional vegetables. People, are also involved in livestock and breeding, trading, fishing, palm oil production as secondary activity.

\subsection{Methods and Data}

The measurement of vulnerability requires for a model, which delivers the structure, context and objectives of the analysis [6]. The different views on vulnerability are displayed in various concepts and frameworks on how to systematize it. [7]. This study relies on Turner et al's framework in which vulnerability to a hazard is understood as an outcome of the interrelationships between exposure, sensitivity and resilience based on the notion of socio-ecology. The social-ecology perspective puts the coupled human-environmental system at the centre of the vulnerability analysis [8]. The study focuses only on the vulnerability part of the framework, highlighted in red on (Figure 2) to develop local indicators to asses and measure the vulnerability of the selected villages. 


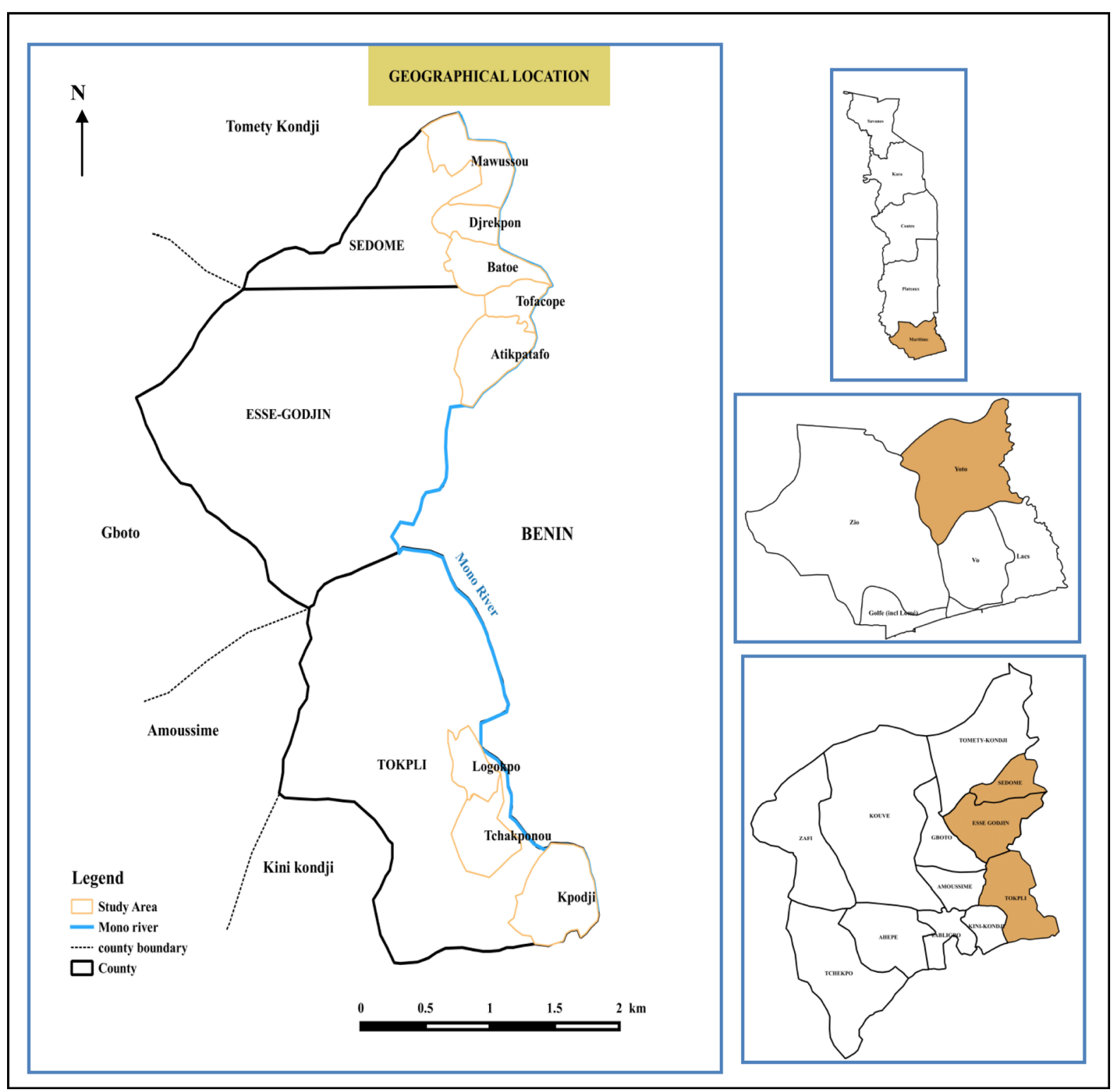

Figure 1. Geographical location of the study area.

The procedures for indicator selection follow two general approaches: deductive and inductive approaches [9]. In deductive approach, indicators are selected based on relationships established from theories and conceptual frameworks whilst inductive approach involves statistical procedures to relate a large number of variables to vulnerability in order to identify the factors that are statistically significant. In this study, indicators were developed base on the deductive approaches to serves as proxies to characterize the communities' vulnerability to flood disasters (Table 1). Those indicators were collected through questionnaire-based interviews at household levels and personal observation. The field survey and interviews that were carried out in the scope of this research showed whether the selected indicators are most relevant for flood vulnerability analysis in the study area taking into account the local knowledge and perception of the affected people.

\subsubsection{Flood Frequency and Magnitude Analysis}

The magnitude of an extreme event is inversely related to its frequency of occurrence, very severe events occurring less frequently than more moderate events [10]. For this study, further insight into flood frequency is provided by the return period analysis. The return period was obtained using the most efficient formula for compu- 


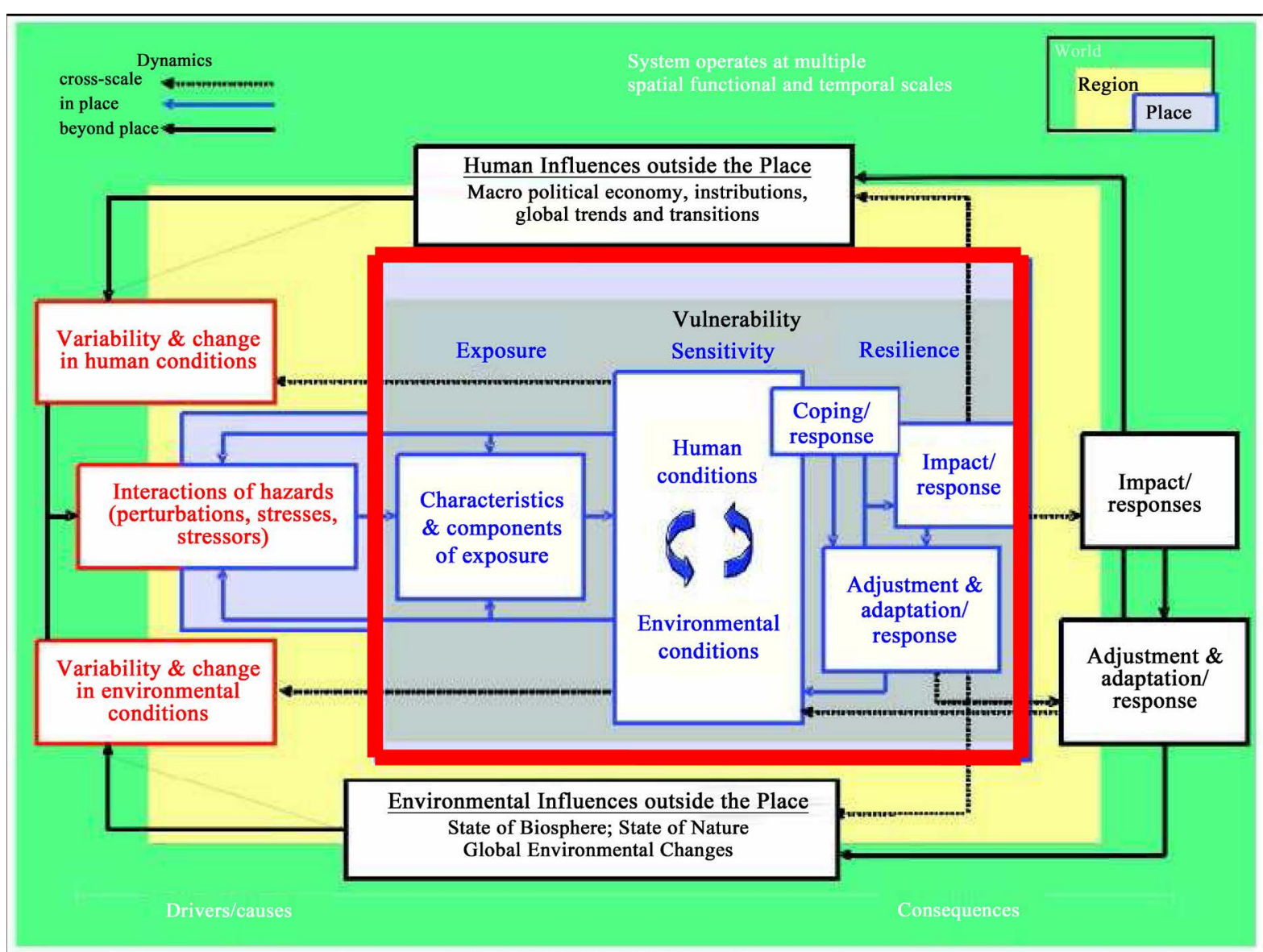

Figure 2. Turner et al.'s vulnerability framework; source: Turner et al., 2003, p. 8076.

Table 1. Selected indicators for flood vulnerability.

\begin{tabular}{cllc}
\hline \multicolumn{1}{c}{ Defined indicator } & Factors & Functional relationship \\
\hline 1 & Flood frequency (year) & Exposure & $(+)$ \\
2 & Flood duration (day) & Exposure & $(+)$ \\
3 & Flood water level (m) & Exposure & $(+)$ \\
4 & Closeness to river body (m) & Exposure & $(+)$ \\
5 & Altitude (m) & Exposure & $(+)$ \\
6 & Education: no schooling (\%) & Susceptibility & $(+)$ \\
7 & Household size (more than 10)\% & Susceptibility & $(+)$ \\
8 & Female headed (\%) & Susceptibility & $(+)$ \\
9 & Farmers (Solely) (\%) & Susceptibility & $(+)$ \\
10 & Poor building material (\%) & Susceptibility & $(+)$ \\
11 & Household with affected land (\%) & Susceptibility & $(+)$ \\
12 & Community Awareness (\%) & Susceptibility & $(+)$ \\
13 & Household Coping mechanisms (\%) & Susceptibility & $(+)$ \\
14 & Emergency service (\%) & Susceptibility & $(+)$ \\
15 & Household Past experience (\%) & Susceptibility & $(+)$ \\
16 & Household Preparedness (\%) & Susceptibility & $(-)$ \\
17 & Warning system (\%) & Resilience & $(-)$ \\
18 & Household perception on flood risk(\%) & Resilience & $(-)$ \\
19 & Household Evacuation capability (\%) & Resilience & $(-)$ \\
20 & Household flood Training (\%) & Resilience & $(-)$ \\
21 & Recovery capacity (\%) & Resilience & $(-)$ \\
22 & Recovery Time (\%) & Resilience & $(-)$ \\
23 & Long term resident 10 years + (\%) & Resilience & $(-)$
\end{tabular}


ting plotting positions for unspecified distributions and commonly used for most sample data: the Weibull Equation (1). The Weibull equation attempts to build the relation between the probability of the occurrence (return period) of a certain event and its magnitude, i.e. derive the frequency of an event of a given magnitude that may be expected in the long-run average. The annual peak discharge data of the Mono River at Athieme station (1971-2010, $\mathrm{N}=40$ years) is selected for flood frequency analysis. A simple technique was to arrange the given peak in decreasing order of magnitude and assigned an order number $(1,2,3, \cdots, n)$. The probability of occurrence for each observation is given by:

$$
P=\frac{m}{N+1}
$$

where: $P$ = Probability of occurrence; $m=$ order number of the event; $N=$ Total number of events in the data.

The return period or recurrence interval or frequency for each observation was determined using the following formula:

$$
T=\frac{1}{P}
$$

Depending on the flood peaks recorded in 2010 for the study area and the average flood peaks for the examined period, floods are classified according to their magnitude.

\subsubsection{Flood Duration and Flood Water Level Assessment}

Data on flood duration and flood water levels were obtained from each household from interview. The interviewed household could recall the peak duration of flooding during the latest more severe flood (2010). The average days recorded from household interviews was calculated for each village. Flood water levels were measured inside the house as revealed by marks on building walls with reference to the ground floor during the interviews. The flood water levels were ranged from the lowest level to the highest level for each village.

\subsubsection{Assessment of Human-Environmental Condition}

The Statistical Package for the Social Sciences (SPSS) is used for data entry and statistical analysis as the methods for human-environmental condition components analysis. It includes descriptive statistics to describe all the data in general.

\subsubsection{Computation of Flood Vulnerability Index (FVI)}

Different methodologies have been used to compute a Flood Vulnerability Index (FVI). All FVI equations have factors for exposure to hazard, sensitivity or susceptibility of the people, and their resilience or coping capacity to the hazard. Vulnerability is the result of the combination of exposure, susceptibility and resilience. The goal of the equation of the FVI is to compare different communes to one another in overall vulnerability, but also in its separate factors exposure, susceptibility and resilience. To make it possible to visualize these separated factors, a summation relationship is more useful. Also, it is preferred if the resilience is negatively formulated, and a higher score causes the vulnerability to be higher, conform other factors. With the chosen equation, the indicators have to be measured on a scale from $0 \%-100 \%$ or $0-1$, like [11].

The collected data were arranged in the form of a rectangular matrix with rows representing villages and columns representing indicators. In order to obtain figures which are free from the units and also to standardize their values, the indicators were normalized so that they all lie between 0 and 1 . After computing the normalized scores the index is constructed by giving unequal weights to all indicators.

Two types of functional relationships are possible: vulnerability increases with increase (decrease) in the value of the indicator. All datasets were normalised, using linear min-max normalization (Equations (3) and (4)) according to (Iyengar and Sudarshan) [12] [13].

The study used then two formulas to normalise indicator, depending on their functional relationship with vulnerability. Then, in case that the indicator has an increase functional relationship with vulnerability (positive indicators), the normalisation is done using the following formula:

$$
Y_{i j}=\frac{X_{i j}-\operatorname{Min}\left(X_{i j}\right)}{\operatorname{Max}\left(X_{i j}\right)-\operatorname{Min}\left(X_{i j}\right)}
$$


On the other hand, in case that the indicator has a decrease functional relationship with vulnerability (negative indicators), the normalized score is computed using the formula:

$$
y_{i j}=\frac{\operatorname{Max}_{i}\left\{X_{i j}\right\}-X_{i j}}{\operatorname{Max}_{i}\left\{X_{i j}\right\}-\operatorname{Min}\left\{X_{i j}\right\}}
$$

$X_{i j}$ denotes the value of $j$ indicator $(j=1,2, \cdots, 24)$ in the $i$ village $(i=1,2, \cdots, 8)$;

$Y_{i j}$ is the matrix corresponding to the normalized score;

$W_{j}$ and $Y_{i j}$ lie between 0 and $1 ; \sum W_{i}=1$.

It is obvious that the scaled values of $Y_{i j}$ lies between 0 and 1 . The value 1 corresponds to that village with maximum value and 0 corresponds to the village with minimum value. Through those formula the normalized scores for each indicator were obtained using MS-EXCEL Max() and Min() functions.

\section{- Method of Weighting and Aggregation of Indicators into Vulnerability Index}

After computing the normalized scores, the index is constructed by giving an unequal weight to all indicators. The present study uses an unequal method of Iyengar and Sudarshan's to give weight to all indicators [12]. In Iyengar and Sudarshan's method, the weights are assumed to vary inversely as the variance over the regions in the respective indicators of vulnerability.

That is, the weight $w_{j}$ is determined by (Equation (5)):

$$
w_{j}=c / \sqrt{\operatorname{var}_{i}\left(x_{i j}\right)}
$$

where $c$ is a normalizing constant: (Equation (6))

$$
c=\left[\sum_{j=1}^{j=K} 1 / \sqrt{\operatorname{var}_{i}\left(x_{i j}\right)}\right]^{-1}
$$

The choice of the weights in this manner would ensure that large variation in any one of the indicators would not unduly dominate the contribution of the rest of the indicators and distort inter regional comparisons. It is well known that, in statistical comparisons, it is more efficient to compare two or more means after equalizing their variances.

The overall village index, $Y_{i}$, also varies from zero (0) to one (1) with 1 indicating maximum vulnerability and 0 indicating no vulnerability at all. The higher the district index, the more the level of vulnerability. The composite indicator for flood vulnerability factors (exposure, susceptibility and resilience) for the ith village was obtained as:

$$
Y_{i}=\sum W_{i} Y_{i j}
$$

where: $Y_{i}$ is the composite indicator of $i$ th village; $W_{j}$ is the weight for each indicator lies between 0 and 1 ; $\sum W_{j}=1$; and $Y_{i j}$ is the normalised scores of indicators.

To ensure that the indices calculated for each vulnerability factor can be compared, the sum for each factor of exposure, susceptibility and resilience are divided by their respective number of indicators that describe each vulnerability factor. The composite vulnerability index for exposure factor is given as:

$$
\text { Clexposure }=\frac{\sum_{e i=1}^{n} W_{j} Y_{i j}}{n}
$$

where: CIexposure is the composite vulnerability index of exposure factor.

$W_{j}$ is the weight a single indicator, $e i$ is exposure indicators; $Y_{i j}$ is the normalised value of exposure indicator; $n$ is the number of indicators.

Susceptibility and resilience factors can all be represented in similar way.

Any flood vulnerability analysis requires information regarding these factors, which can be specified in terms of exposure indicators, sensitivity indicators and resilience indicators. Finally, the vulnerability of a system to flood events can be expressed with the following general equation [14]. This equation is used in the present study to compute Flood Vulnerability Index (FVI).

$$
\text { Vulnerability }=\text { Exposure }+ \text { Susceptibility }- \text { Resilience }
$$


The composite index values of the three factors of vulnerability and total flood vulnerability index values were integrated in ArcGIS 10.1 software with all relevant input data being available in a digital spatial database (polygon shape file) to produce exposure, susceptibility, and resilience and vulnerability maps. The maps were classified and colour coded green-yellow-red, indicating low-moderate-high areas, respectively.

\section{Results and Discussions}

\subsection{Flood Frequency and Magnitude Analysis}

The return period and the probability of occurrence for each observation of the Mono River have been computed, using Weibull's formula, for the period 1971-2010 which generally starts to peak in the month of July with the maximum in the month of September according to flood hydrology data of Athieme station.

The Mono River discharge at the downstream reveals that the study area has been affected 22 times by low floods with magnitude ranging between $\left(69.16-372.33 \mathrm{~m}^{3} / \mathrm{s}\right)$, nine times by moderate floods with magnitude between $\left(372.34-549.64 \mathrm{~m}^{3} / \mathrm{s}\right)$ and nine times by high flood events with magnitude ranging between (549.65 $736.70 \mathrm{~m}^{3} / \mathrm{s}$ ) (Figure 3).

The low floods have return periods of 1 or 2 years with high probability of occurrence, the moderate floods have a return period of 2, 3, 4 years with probability of occurrence less than $50 \%$. The most severe flood event occurred in the study area is the 2010 one. Flood as a same magnitude have $22 \%$ of chance to occurred once in five years. During the record period, the recurrence interval of high flood based on the 2010 flood magnitude has ranged from 5 to 41 years.

\subsection{Flood Duration and Flood Water Level Assessment}

Even though the surveyed villages are exposed to the same hazards, the flood water level and flood duration are different from one village to another (Table 2). The result reveals that the higher the flood waters level, the higher

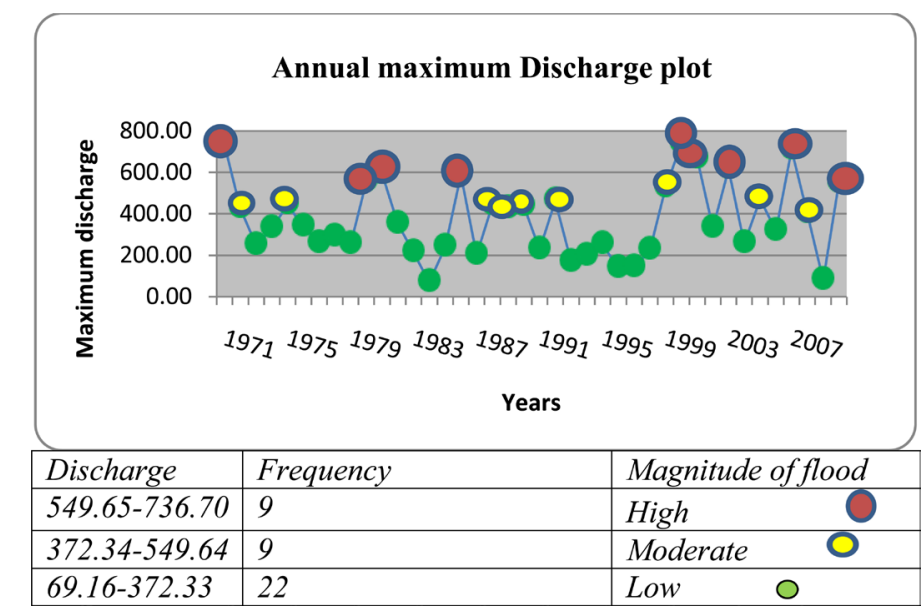

Figure 3. Flood frequency and flood magnitude for the period 1971-2010.

Table 2. Depths of flood water (2010) as revealed by marks on building walls average flood duration (2010) from household and the proximity to the river.

\begin{tabular}{cccc}
\hline Flooded areas & Depth of flood marks on walls (2010) & Flood duration (days) (2010) & Proximity to the river body (m) \\
\hline Djrekpon & $63-99 \mathrm{~cm}$ & 58 & 470.35 \\
Batoe & $50-118 \mathrm{~cm}$ & 82 & 303.79 \\
Logokpo & $70-100 \mathrm{~cm}$ & 88 & 909.28 \\
Tchakponou & $50-106 \mathrm{~cm}$ & 80 & 626.13 \\
Kpodji & $57-170 \mathrm{~cm}$ & 95 & 1874.22 \\
Tofacope & $30-45 \mathrm{~cm}$ & 41 & 112.54 \\
Atikpatafo & $65-70 \mathrm{~cm}$ & 71 & 165.55 \\
Mawussou & $45-65 \mathrm{~cm}$ & 51 & 435.55 \\
\hline
\end{tabular}


the flood duration. It was noticed that villages such as Kpodji, Tchakponou and Logokpo have the highest flood level and highest flood duration although they are most distantes from the Mono River bed. This can be explained by the fact that these villages are made up by heavy soil which can decrease the flood water infiltration capacity and increase the duration of flood water in the area.

In addition, the surveyed villages are closer to the river. The distance is comprised between $(100-2000 \mathrm{~m})$ (Table 2) and the villages lie in the low altitude level of the Yoto district.

The extreme variability of the river discharge in terms of flood frequency and flood magnitude coupled with the closeness and low altitude of the surveyed villages makes the surveyed villages highly exposed to flood hazards.

\subsection{Assessment of Human-Environment Vulnerability}

The study focuses on two main elements at risks: households and their agriculture croplands. As it is shown in various studies and confirmed by the majority of the respondents $72.36 \%$, women, children and elderly are considered as the most exposed to flood due to their fragility. It was found also that the surveyed households were having agriculture croplands of about 506 ha of which the majority is very closer to the river body (less or equal to $200 \mathrm{~m}$ ). The crop production activity in the study area depends on rainfall and practices which is still traditional with rudimentary tools. Farmers are faced with problems of storage and preservation of harvested crops. Thus, when flood came, before and even after harvesting period, the majority of crops are destroyed. Since the crop production is the main source of income and food, added to the high number of household member, increased exposure to floods will exacerbate the population vulnerabilities to flood hazards by compromising their food security. In addition, the majority of the respondents have low level education (39.8\%) attained only primary education as their highest level. As observed during the field survey, most of the settlements are located near the river as the river is the main source of water in the study area. The proximity to the river body facilitates the access to water for their various activities. The majority of the households interviewed $(74.7 \%)$ lived in building made up of clay walls with thatched roof which are very susceptible to flood hazard. Furthermore, the lack of adequate flood warning system and the lack of willingness and ability to take responsive actions coupled with inadequate emergency services during and after flood, may increase the communities' vulnerability to flood disasters. The extent of environmental degradation has also an important role to play in exacerbating community vulnerability. The field survey revealed that the study area is subjected to the fragmentation of the river bank digging and widening the river channel. The removing of vegetation along the river bank which leaves the soil to be exposed, increase surface runoff and then flood extent.

\subsection{Computation of Flood Vulnerability Index (FVI)}

The exposure factor considers the indicators which explain how social entities such as households or economic activities like agriculture, etc., are exposed to flood events. Five (05) indicators are used to explain the determinant of communities' vulnerability to flood disaster under exposure factor. The composite vulnerability index of this factor is calculated for each village. By considering the composite index of exposure factor, the most exposed villages are Djrekpon and Kpodji with high indices ranging from 0.0451 to 0.0651 (Figure 4). The most exposed villages have the highest scores for most of the considered indicators under the elements at risk compared to the other villages: high population and farmland in flooded area, high percentage of women and children and elderly in flooded area.

The Susceptibility factor considers the indicators which evaluate the sensitivity of an element at risk before and during a flood event. Eleven (11) indicators are also equally used to explain the determinants of communities' vulnerability to flood disasters under susceptibility factors. The composite index of susceptibility factor for each village is computed. By considering the composite index of susceptibility factor, the most susceptible villages are Batoe and Atikpatafo with high indices ranging from 0.0058 to 0.0065 (Figure 5). The most susceptible villages have the highest scores for most of the considered indicators: high female headed household, low education level, limited livelihood strategies, high household size, low coping capability, low access to emergency service, low preparedness capability.

The resilience factor considers indicators which clarify the ability of a Human-Environment system to persist if exposed to flood by recovering during and after the event. Eight (08) indicators have been used to explain the determinants of communities' vulnerability to flood disasters under resilience factor. The composite index of 
susceptibility factor for each village is computed. By considering the composite index of resilience factor, the least resilient villages are Djrekpon, Tchakponou and Kpodji with indices ranging from (0.0059 - 0.0069) (Figure 6). The least resilient villages have the lowest scores for most of the considered indicators: Low knowledge on warning system, low evacuation capability, low recovery capacity.

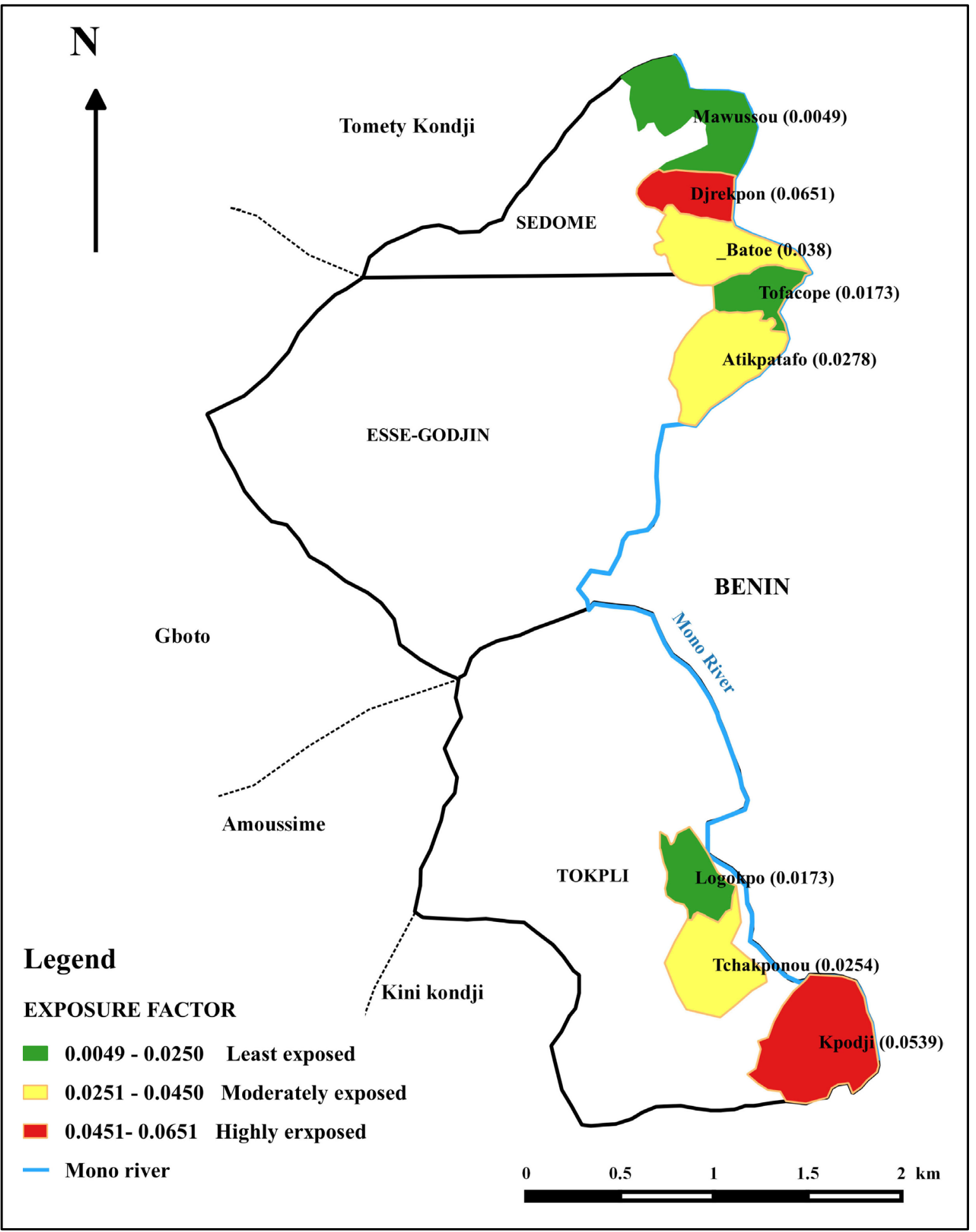

Figure 4. Flood exposure map of the study area. 
The values of the indicators were used in the vulnerability's equation (Equation (9)) to determine the overall flood vulnerability index. Among the eight villages surveyed, Djrekpon and Kpodji are found to experience relatively high vulnerability with indices ranging from (0.0048 - 0.0225), Batoe, Atikpatafo, Logokpo and Tchakponou are found to be moderately vulnerable with indices ranging from $(0.0256-0.461)$ and Mawussou and Tofacope are estimated to suffer relatively low level of vulnerability to flood disaster with indices ranging from (0.462 - 0.668) (Figure 7).

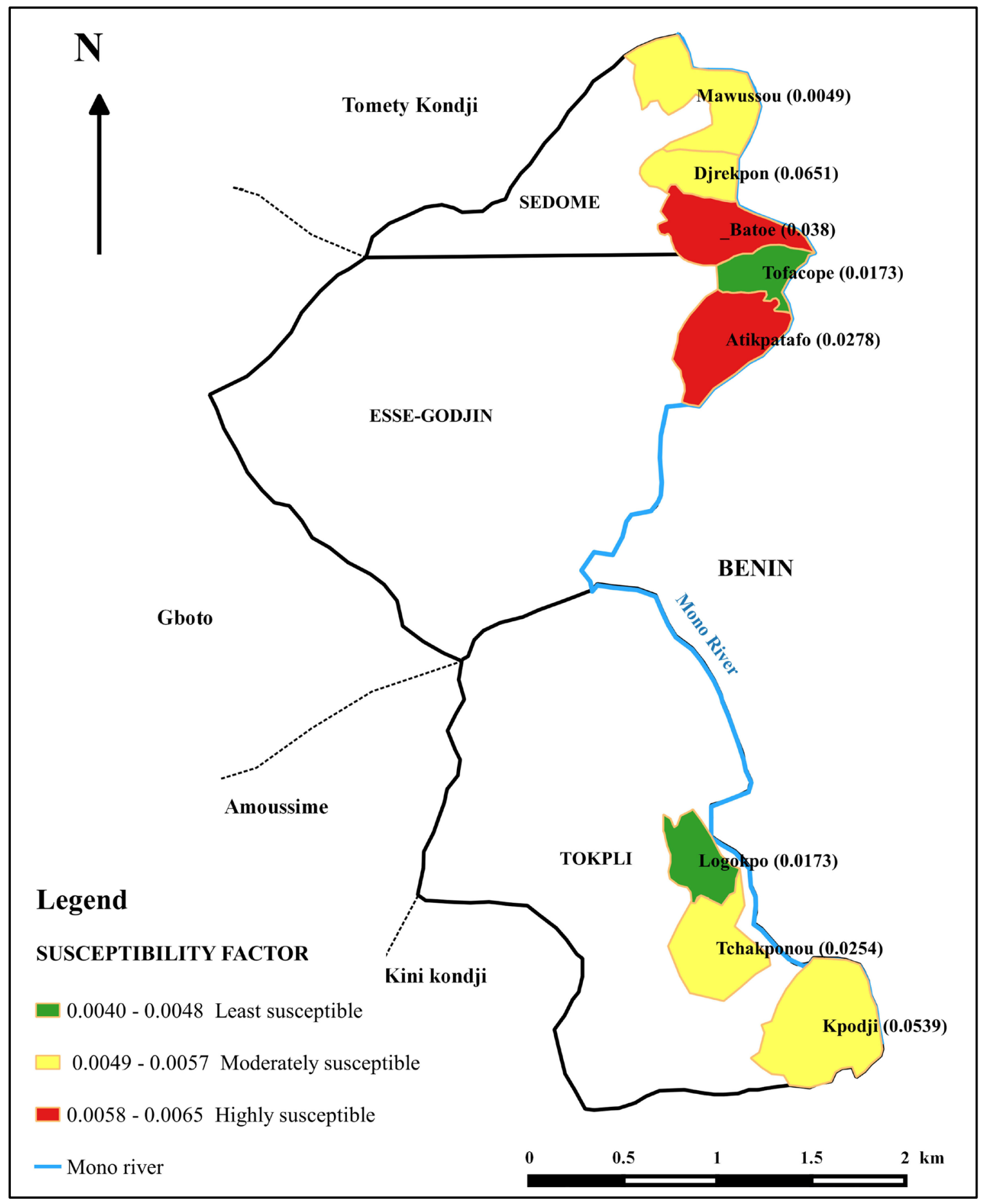

Figure 5. Flood susceptibility map of the study area. 


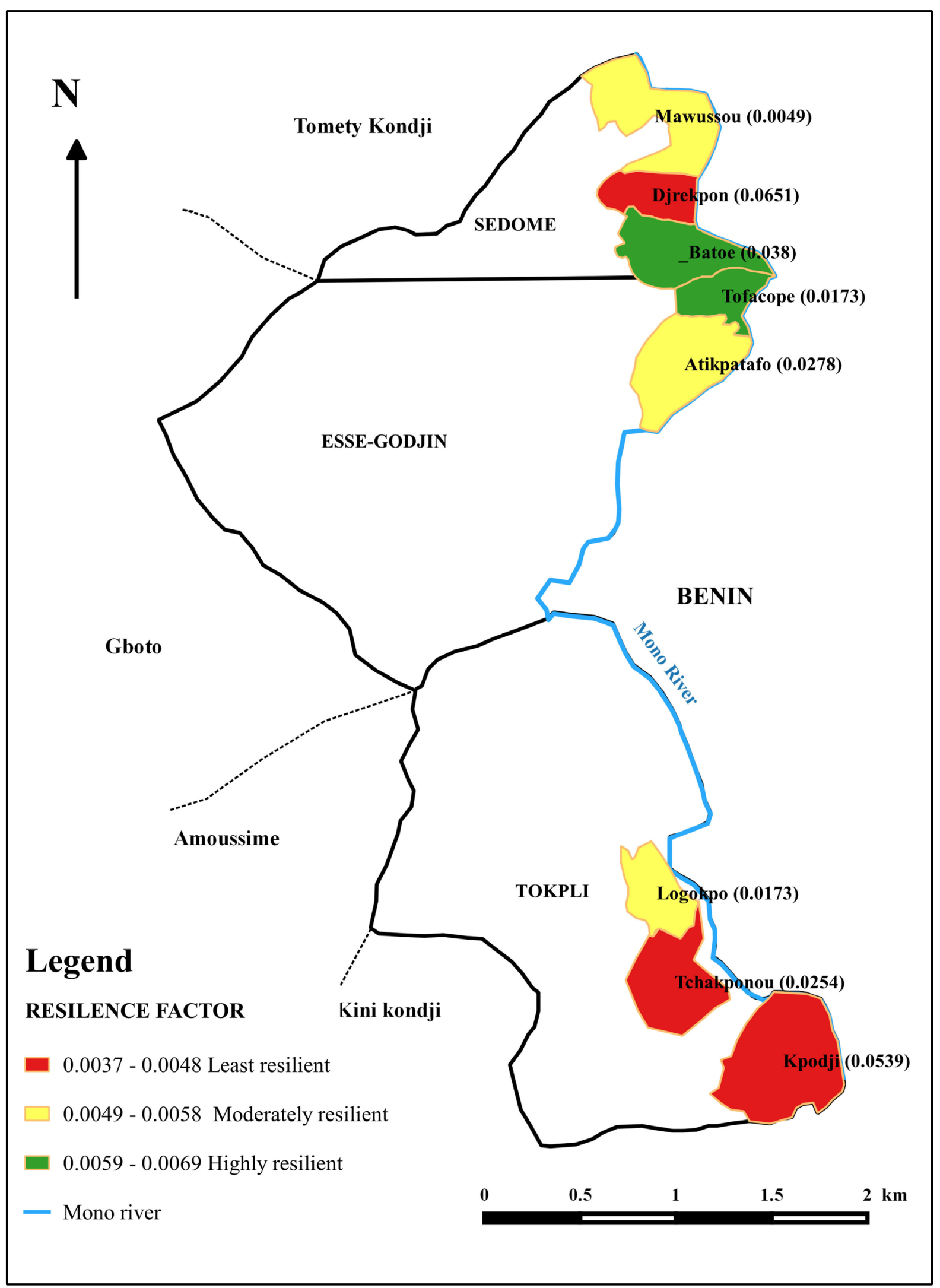

Figure 6. Flood resilience map of the study area. 


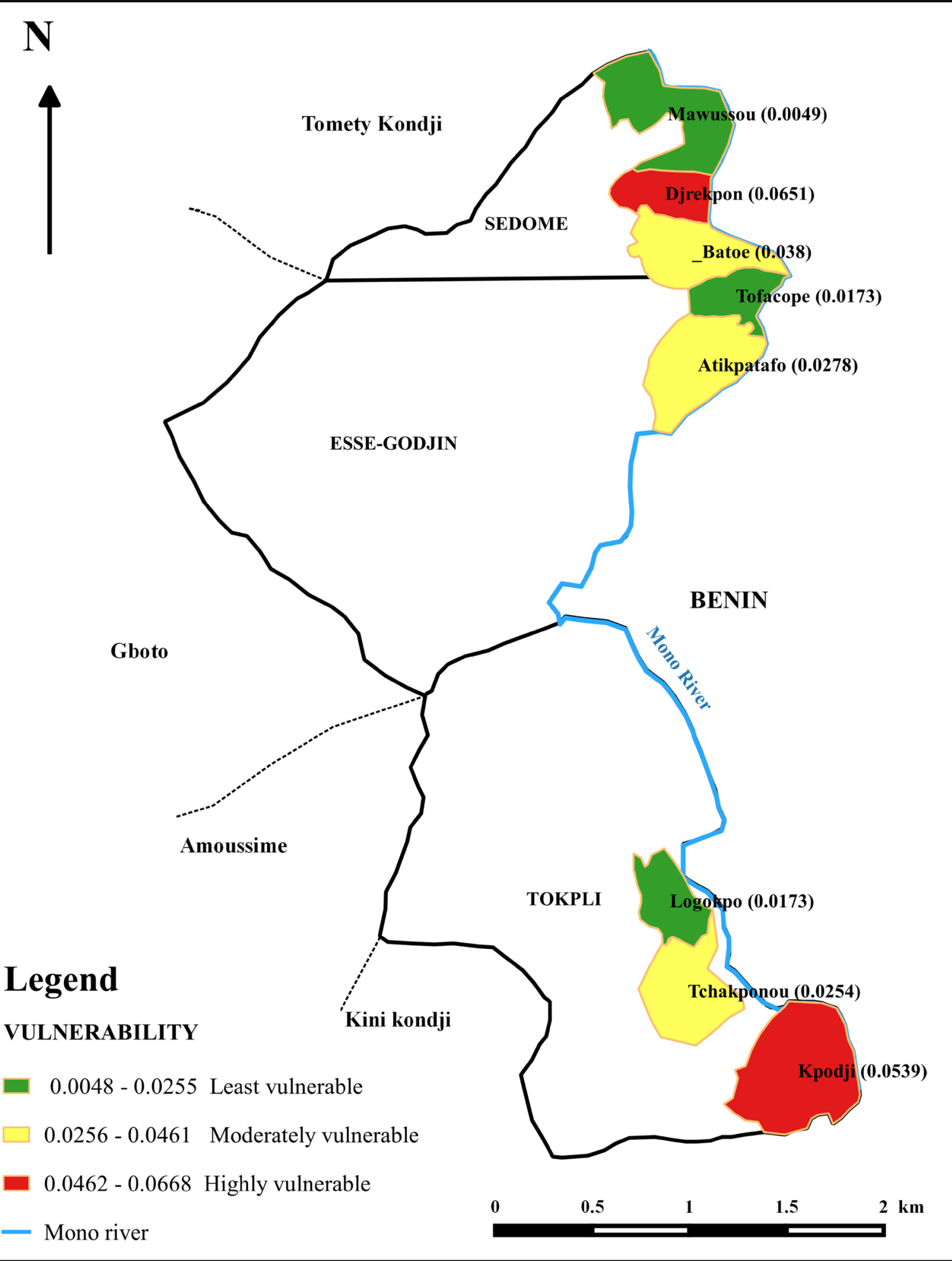

Figure 7. Flood vulnerability map of the study area.

\section{Conclusion}

The assessment of the vulnerability of the downstream area of Mono basin in Yoto district to flood presented in 
this paper is based on the Turner et al. 2003 framework and integrates quantitative data on human-environmental dimensions of vulnerability. This allowed consideration of a broader set of drivers and elements that come into play in determining the most vulnerable villages among the eight surveyed villages of the study area. The overall FVI has shown two most vulnerable villages: Djrekpon and Kpodji. It is found that Djrekpon and Kpodji villages were highly exposed, Djrekpon was highly susceptible and Kpodji was moderately susceptible while the two villages were found to be least resilient. Some justification can be found in these results by looking at the number of households affected by floods during the last ten years, the high percentage of household heads with no education level, the lack of livelihood strategies option of those households, the highly susceptible building materials, the lack of adequate coping capacity and recovery capacity from floods.

\section{Acknowledgements}

We express our thanks to WASCAL, BMBF, Prof. Kouami Kokou, Prof. Adote Blim Blivi.

\section{References}

[1] Sadiq, I.K., Hong, Y., Wang, J., Koray, K., Yilmaz, J., Gourley, J., Robert, F., Adler, G., Brakenridge, R., Fritz, P., Shahid, H. and Irwin, D. (2011) Satellite Remote Sensing and Hydrologic Modeling for Flood Inundation Mapping in Lake Victoria Basin: Implications for Hydrologic Prediction in Ungauged Basins. Transactions on Geoscience and Remote Sensing, 49, 85-91. http://dx.doi.org/10.1109/TGRS.2010.2057513

[2] Balica, S.F., Douben, N. and Wright, N.G. (2009) Flood Vulnerability Indices at Varying Spatial Scales. Water Science and Technology, 60, 2571-2580. http://dx.doi.org/10.2166/wst.2009.183

[3] Carter, W.N. (1991) Disaster Management, Disaster Managers’ Handbook. Publication of the Asian Development Bank, Manila.

[4] IPCC (2007) Climate Change 2007: Impacts, Adaptation and Vulnerability. Contribution of Working Group II to the Fourth Assessment Report of the Intergovernmental Panel on Climate Change. Cambridge University Press, Cambridge.

[5] Ago, E.E., Petit, F. and Ozer, P. (2005) Analyse des inondations en aval du barrage de Nangbéto sur le fleuve Mono (Togo-Bénin). Géo-Eco-Trop, 29, 1-14.

[6] Fekete, A. (2010) Assessment of Social Vulnerability for River Floods in Germany. Graduate Research Series, 4, Bonn, UNU-EHS.

[7] Birkmann J. (2013) Measuring Vulnerability to Natural Hazards: Towards Disaster Resilient Societies. 2nd Edition, United Nation University, Tokyo.

[8] Turner, B.L., Kasperson, R.E., Matson, P.A., McCathy, J.J., Corell, R.W., Christensen, L., Wisner, B., Blaikie, P., Cannon, T. and Davis, I. (2003) At Risk: Natural Hazards, Peoples' Vulnerability and Disasters. Routledge, London.

[9] Adger, W.N., Brooks, N., Bentham, G., Agnew, M. and Eriksen, S. (2004) New Indicators of Vulnerability and Adaptive Capacity, Tyndall Centre for Climate Change Research. Technical Report 7, Norwich.

[10] Maiti, S. (2007) Defining a Flood Risk Assessment Procedure Using Community Based Approach with Integration of Remote Sensing and GIS-Based on the 2003 Orissa Flood. Master's Thesis, India Institute of Remote Sensing, the Netherlands.

[11] Balica, S.F., Wright, N.G. and Vander Meulen, F. (2012) A Flood Vulnerability Index for Coastal Cities and Its Use in Assessing Climate Change Impacts. Natural Hazards, 64, 73-105. http://dx.doi.org/10.1007/s11069-012-0234-1

[12] Iyengar, N.S. and Sudarshan, P. (1982) A Method of Classifying Regions from Multivariate Data. Economic and political weekly, 17, 2048-2052.

[13] Kumar, P., Paul, K.S.R., Kruhna, R.K., Rao, D.V.S. and Chandra, S.R.M. (2014) Assessment of Vulnerability and Impact of Climate Change on Crop Production in Krishna River Basin of Andhra Pradesh. International Journal of Current Agricultural Research, 3, 062-066. http://dx.doi.org/10.5958/j.0976-058X.48.1.011

[14] Balica, S.F. (2007) Development and Application of Flood Vulnerability Indices for Various Spatial Scales. Master's Thesis, UNESCO-IHE Institute for Water Education, the Netherlands. 